This text is licenced under CreativeCommons Attribution-NonCommercial-ShareAlike 3.0.

It is a chapter in White Spaces in the Developing World, edited by Ermanno Pietrosemoli, to be published in the summer of 2013 by the Telecommunications/ICT for Development Laboratory, Abdus Salam International Centre for Theoretical Physics, Trieste, Italy

\title{
Geo-Database Management of White Space vs. Open Spectrum
}

\author{
by Robert Horvitz \\ bob@openspectrum.info
}

\begin{abstract}
"The whole tendency of radio development has been in the direction of increasingly rigid control by patriotic politicians, who have been almost literally sitting on the doorsteps of the laboratories waiting for the technicians to appear with their inventions. It may have been to radio's advantage in a purely physical sense that it came into existence during the period of intense national rivalry which preceded the...war of 1914-1918, but the coincidence meant that radio became identified from the start with patriotic service to the state. No other means of communication provoked intervention by the state as quickly as did radio."
\end{abstract}

---O. W. Riegel, Mobilizing for Chaos (Yale University Press, 1934)

Since the beginning of the $20^{\text {th }}$ century, the use of radio has been more strictly regulated than any other medium of communication. Essentially everything is forbidden which is not explicitly authorized by your country's government. Students of comparative law will immediately recognize that as the "authoritarian" model, and it is found today even in the most liberal democracies.

Why is that? History shows that the policy of strict governmental control is the result of 3 factors which existed when radio's first practical application emerged.

One factor was the national security importance of radio's first application, wireless telegraphy. Wire telegraphy had been a revolutionary development 50 years earlier and its links had already spread across all lands. But communicating with vessels on the high seas remained impossible until a teenage experimenter named Guglielmo Marconi figured out how to do it and made it into a business. ${ }^{1}$ Marconi's achievement - and the frequent publication of plans in books and magazines explaining how to build simple transmitters and receivers inspired youngsters around the world to start experimenting with radio. ${ }^{2}$ That aroused fears about interference to diplomatic and naval message traffic, hoaxes and false emergencies being reported, messages not addressed to the public being intercepted, SOS calls being missed, etc.

So the second contributing factor was the immaturity of radio technology in those early days. Compared with what we have today, early radio equipment was dumb and primitive.

Therefore, the equipment operators had to be disciplined and skillful in order to prevent chaos from making the airwaves unusable. Government regulation was another way to compensate for the hardware's inadequacy.

\footnotetext{
${ }^{1}$ Nikola Tesla proposed and demonstrated practical uses for radio before Marconi but gave his attention to the development of electrical power instead.

${ }^{2}$ Books and magazines popularizing radio were as common in the first decade of the $20^{\text {th }}$ century as books and magazines about personal computers in the 1980s.
} 
The third contributing factor was Marconi's solution to the problems of interference, spectrum chaos and public access to private messages: a global monopoly in radio services. The Marconi Wireless Telegraph Company claimed its patents were so fundamental that no one else had the right to produce or receive radio waves (amateur experimenters were tolerated, however, so long as they weren't paid for services). But governments did not want to depend on a foreign commercial monopoly to communicate with their own navies, so they pushed back with a treaty establishing national sovereignty over the radio spectrum, declaring that only governments had the right to regulate and authorize spectrum use. ${ }^{3}$ Amateurs were allowed to continue experimenting but only under government license.

It is important to note that claims of national sovereignty and government exclusivity in the regulation of spectrum access are not based on the physical qualities of radio waves. Radio is the same "stuff" as light ${ }^{4}$ and no nation claims sovereignty over the colors we see, or says it owns the sunlight within its borders, or requires its citizens to get licenses for the use of candles or lightbulbs. It is often noted that radio waves do not respect national borders. That is more than a minor inconvenience, it is proof that government efforts to monopolize and doll out access to the radio spectrum derive not from physics but from a political agenda.

The key point in this discussion is that a strict authoritarian approach to regulation of radio is not inevitable, it is the result of particular historical circumstances, including the state of technology, which can change. Indeed, circumstances have changed. No company today can assert a patent monopoly over radio. Most radio uses now are short-range and personal, for business or entertainment, with no impact on national security. Pre-registration of channel assignments and official interventions to resolve interference complaints are rare now that "smart" radios have built-in channel selection and interference avoidance mechanisms. Yet the old habits and laws persist.

In 1938 the US Government acknowledged that it was impossible to license every radio source (every wire carrying electricity emits radio waves), nor was it even necessary when there was little risk of harmful interference. A previously unexploited loophole in the international radio treaty ${ }^{5}$ let the FCC create a new rule freeing a few specific types of shortrange communication from licensing: baby monitors, wireless loudspeakers for gramophone

\footnotetext{
3 "International Radio Telegraph Convention of Berlin: 1906" (Washington, DC, USA: Government Printing Office, 1912) - http://www.itu.int/ITU-R/information/promotion/100-years/documents/1906Berlin-E.pdf. To dispel any doubt that it was Marconi's business practices and monopoly ambitions which led to the regulation of radio, here is an account by the International Telecommunication Union's historian:

"The aim of the German Government in calling the [first international conference on radio] was clear from the beginning. The chief of the German delegation, and president of the Conference, in his opening remarks stated that the development of radio, which was still in its infancy, would be unduly hampered by any attempt to monopolize facilities and that, therefore, rules should be made to block any attempt to impose one system upon others. His attack was made directly at the Marconi Company, and the Marconi Company's restrictive practices were cited as an example of an attempt to force one system on all the world."
}

Quote from The International Telecommunication Union: An Experiment in International Cooperation by George A. Codding Jr., (New York, NY USA: Arno Press, 1972, reprint of the E. J. Brill edition, 1952), page 84 .

${ }^{4}$ Radio is accurately described as colors that the eye cannot see.

${ }^{5}$ A simplified summary of the loophole: nations can depart from the international radio treaty so long as interference is not caused to licensed stations in other countries. 
disk players, "carrier current" broadcasting stations, etc. For decades, the US was the only country that had such a rule. ${ }^{6}$

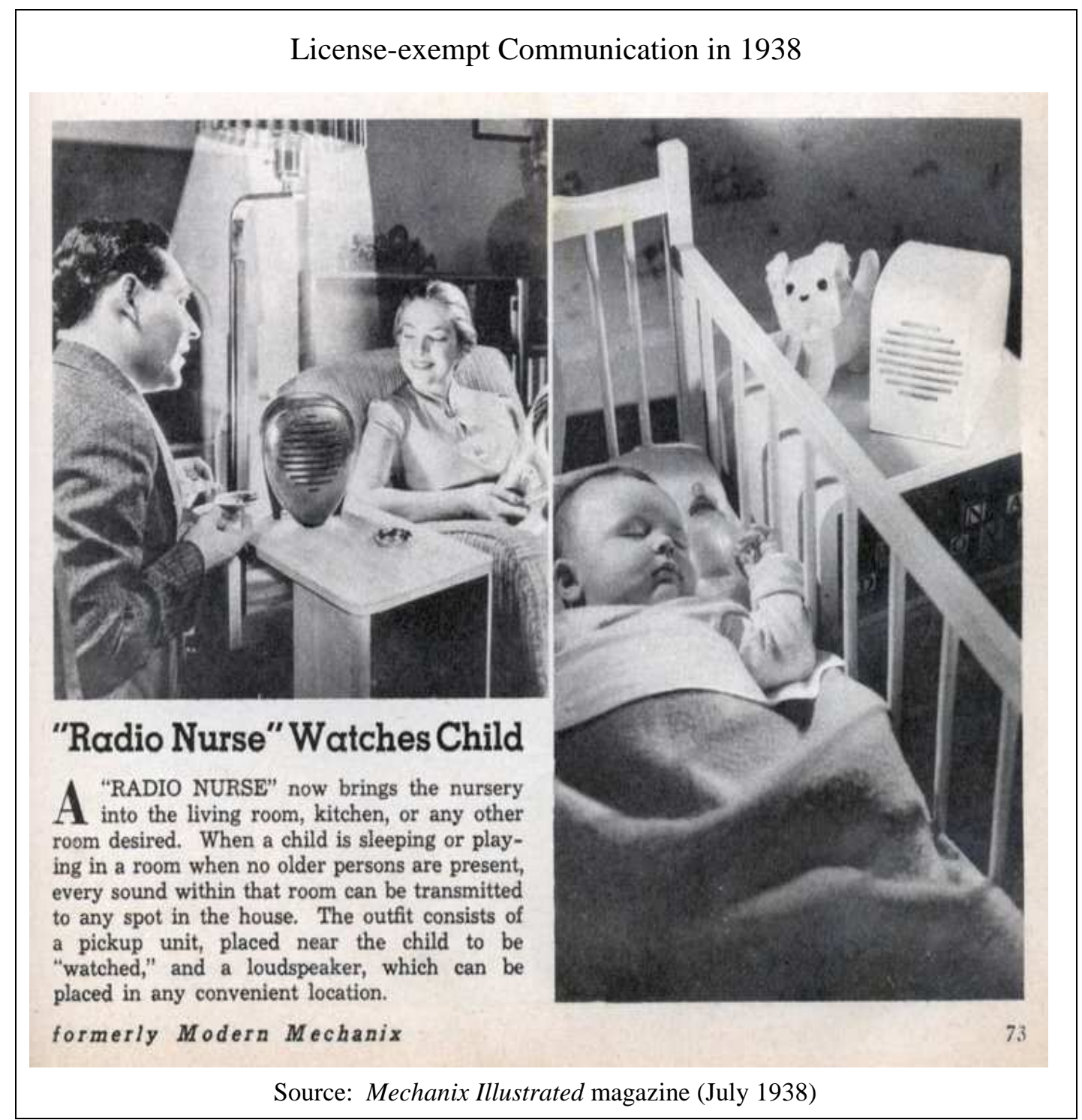

As time went by, additional manufacturers sought exemption from licensing for their radio products and the FCC considered each request individually. By the 1980s, the backlog of pending applications was large and the inconsistencies among earlier decisions begged for explanation. So in 1989 the FCC "future-proofed" its rules for license exemption by scrapping most that were application-specific, replacing them with broad categories and application-neutral rules concerning power output, bandwidth, duty cycle, out-of-band emissions, etc. That meant they no longer had to evaluate the merits and public interest in each new product to decide if it was needed. From now on, so long as the equipment satisfied certain technical constraints, the market would decide if it was needed.

This new approach led to a burst of innovation unlike anything seen since the earliest days of radio. RFID, Wi-Fi, Bluetooth and Nintendo's Wii console are some of the best known successes, with hundreds of millions of new devices sold each year. But cordless phones,

\footnotetext{
${ }^{6}$ For insight into the evolution of license-free radio in the US, see Kenneth R. Carter, "Unlicensed to Kill: A Brief History of the FCC's Part 15 Rules," info, Volume 11, Number 5 (2009), pages 8-18 http://ssrn.com/abstract=1120465
} 
"smart" wireless electricity meters, tire pressure monitoring systems, tele-medicine applications and so on also have growing impact. In the future we are likely to see Google Glass, "smart environments" laced with wireless sensors, cars which communicate with the roadway and with each other to ensure traffic safety, and billions of objects and machines linked to the Internet. As the head of Ericsson put it, "everything that needs to be connected will be connected." Of course, that assumes nearly all wireless links will be unlicensed, since there is no way for regulators to process billions of license applications.

Two decades ago, in most countries, unlicensed radio was simply illegal. In a few others, it was a daring exception to the norm of licensed services. Now, thanks largely to Wi-Fi and RFID's global acceptance, most countries have license-free bands. And in a few places (Europe and the US), license exemption is increasingly recognized as the new norm, with licensed radio services a shrinking part of the wireless ecosystem. ${ }^{8}$

This chart shows global sales of unlicensed devices overtaking sales of licensed equipment between 2008 and 2014. (The second pair of bars, devices containing both licensed and unlicensed radios, represents cellular handsets. $)^{9}$



Success in the marketplace usually impresses regulators more than intellectual arguments, and the overwhelming popularity and obvious benefits of $\mathrm{Wi}-\mathrm{Fi}$, and the many applications it enables, make a compelling argument for further relaxation of radio licensing rules. At the same time, the small number of interference complaints generated by Wi-Fi neutralizes the main argument against relaxation.

But even before Wi-Fi existed, two people raised the level of discourse, from the practical question of whether licensing was necessary for a given application, to the general question of what is the best paradigm for future management of the radio spectrum.

\footnotetext{
${ }^{7}$ Nithyasree Trivikram, "Ericsson CEO reveals broadband vision," ITP.net (14 February 2011) http://www.itp.net/mobile/583916-ericsson-ceo-reveals-broadband-vision

${ }^{8}$ The European Union's Authorisation Directive (2002) established “general authorisation” (exemption from licensing) as the preferred approach to regulating radio use: "Member States shall, where possible, in particular where the risk of harmful interference is negligible, not make the use of radio frequencies subject to the grant of individual rights of use [licensing] but shall include the conditions for usage of such radio frequencies in the general authorisation..." Quoted from Article 5, paragraph 1 of "Directive 2002/20/EC of the European Parliament and of the Council of 7 March 2002 on the authorisation of electronic communications networks and services" - http://eurlex.europa.eu/LexUriServ/LexUriServ.do?uri=OJ:L:2002:108:0021:0021:EN:PDF

${ }^{9}$ Chart from Richard Thanki, "The economic value generated by current and future allocations of unlicensed spectrum,” Perspective Associates (2009) - http://apps.fcc.gov/ecfs/document/view? $\underline{\mathrm{id}=7020039036}$ On a per MHz basis, the economic contribution of some unlicensed devices (RFID and Wi-Fi) already exceeds the economic contribution of the most highly valued licensed applications (cellular mobile and television).
} 
Paul Baran is best known as the engineer who developed "packet switching" in the 1960s. This is a flexible and highly efficient way to optimize the movement of data between nodes in a network. A remarkable feature of packet switching is that it enables networks to resist and overcome disruption without any traffic control center. The Internet is the best known implementation of packet switching. Its efficiency, flexibility, resilience and lack of centralized control have transformed communications - as well as the way knowledge is shared, business is conducted, entertainment is delivered, countries are governed, etc.

Baran's research suggested that the same principles which make packet switching resilient and efficient should work whether the net links are wired or wireless. That led him to consider the possibility of regulating radio under Internet-like rules. Might Internet-like benefits come from eliminating radio control centers?

Baran first offered these ideas publicly at a conference on Next Generation Networks in November 1994, then again, in more polished form, at the Marconi Centennial Symposium in Bologna, Italy, in June 1995, where he was the keynote speaker. His second presentation is quoted here:

"It is my belief that public policy might be better served if we moved to an environment of near zero regulation. In such an environment anyone and everyone would be allowed to use the spectrum, without the barriers to entry that keep out the true innovators. Of course, there will be some minimal rules necessary, such as maximum allowable transmitted power and power densities. The micro-managed regulatory approach of today, such as who can use any single frequency is neither necessary nor desirable...

"Would this laissez faire form of regulation lead to chaos? Possibly, but most likely not. Consider the many millions of cordless telephones, burglar alarms, wireless house controllers and other appliances now operating within a minuscule portion of the spectrum and with limited interference to one another. These early units are very low power 'dumb devices' compared to equipment being developed, able to change their frequencies and minimize radiated power to better avoid interference to themselves and to others. Of course that means that there will have to be enough frequency spectrum set aside to do so. But, once having done so, we would have created a communications environment able to handle orders of magnitude more communications than today...

"The Internet provides an instructive model for the future of telecommunications regulations... In the Internet, there is no central node, and only a minimal centralized management structure, limited to a few housekeeping functions... This lack of a limiting centralized structure has permitted the Internet to be responsive to a very large unregulated constituency and allowing explosive growth and with increasing usefulness to its users...

"Will [this approach] work for regulating the radio spectrum? ...Which frequency to use and when, or which form of modulation to use would be left to each user... Inexpensive microcontrollers would be used that first listen and then automatically choose preferred frequencies to avoid other signals in the band. It is really a matter of being a good neighbor. The smart transmitter reduces its power level to that needed to produce an error free signal and no more. A pristine pure slice of spectrum to have error-free performance is not required when using digital modulation. Digital logic on a chip implements error correcting codes to convert a small amount of redundancy 
in transmission enabling even highly corrupted signals to be cleaned up to emerge error free...."10

A few months later, Eli Noam, an American academic and radio amateur who worked for a while in a regulatory agency, built on Baran's ideas, giving them a free-market twist and introducing the phrase "open spectrum." Noam is also worth quoting at length:

"[Radio license auctions] are good for now, but there is a better next step, a freemarket alternative to the present auction system: an open entry spectrum system. In those bands to which it applies, nobody controls any particular frequency. In this system no oligopoly can survive because anyone can enter at any time... There is no license, and no up-front spectrum auction. Instead, all users of those spectrum bands pay an access fee that is continuously and automatically determined by the demand and supply conditions at the time, i.e. by the existing congestion in various frequency bands. The system is run by clearinghouses of users....

"To allocate access one need not grant permanent allocation rights, but rather to charge an access fee that is set dynamically at a level where the available capacity is fully utilized. The access fee would be an 'edge price,' and give any users of the spectrum the right to enter information into the spectrum 'cloud.' Because demand for transmission capacity varies, the access fee would also vary - a high fee where demand is high, and zero when there is excess capacity...

"In 1995, the computer company Apple applied to the US government to allocate a spectrum band for all types of new digital applications, and open to all comers. Why not expand this concept and dedicate a few bands to the open-access, access-price model... Better to approach spectrum use in a pragmatic and searching fashion than with an ideological mind set that equates the free market with one and only particular technique. Auctions are fine for today, but we should be ready to take the next step....

"[T]he proposed open spectrum access system will not be adopted anytime soon. But its time will come, and fully bring the invisible hand to the invisible resource."11

Note that neither Baran nor Noam argue for zero regulation. Both support minimal regulation, without agreeing on what that means. Baran's model is based on the Internet, where contention is resolved statistically, without pricing, while Noam's is based on a frictionless free market, with dynamic pricing. But both would agree there's room for more than one minimalist approach.

In May 2001, New York University's Information Law Institute and Harvard University's Berkman Center for Internet and Society, organized a meeting to launch the Open Spectrum Project, whose aim was "to understand what is the best regulatory environment for licensefree operation and to place that understanding on the public agenda. The project brings together engineers, economists, technologists, and communications law specialists to design the best of all possible regulatory worlds, and to identify viable alternatives to that best

\footnotetext{
${ }^{10}$ Paul Baran, "Is the UHF Frequency Shortage a Self Made Problem?" Marconi Centennial Symposium, Bologna, Italy (23 June 1995) - http://wireless.oldcolo.com/course/baran2.txt

${ }^{11}$ Eli M. Noam, "Taking the Next Step Beyond Spectrum Auctions: Open Spectrum Access," IEEE Communications Magazine, Volume 33 (December 1995) - http://www.columbia.edu/dlc/wp/citi/ citinoam21.html
} 
case." 12 This meeting marked the beginning of Open Spectrum as a movement and those who attended became leading spokesmen for this new paradigm. Some of the core texts produced by the attendees include:

Yochai Benkler, "Some Economics of Wireless Communications," Harvard Journal of Law \& Technology, Volume 16, Number 1 (fall 2002), pages 25-83 http://jolt.law.harvard.edu/articles/pdf/v16/16HarvJLTech025.pdf

Dale Hatfield, "Spectrum Management Reform and the Notion of the 'Spectrum Commons'," Southern African Journal of Information and Communication, issue number 4 (spring 2005) - http://link.wits.ac.za/journal/j0401-hatfield-spectrum.pdf

Kevin Werbach, "Open Spectrum: The New Wireless Paradigm," New America Foundation, Spectrum Series Working Paper \#6 (October 2002) http://werbach.com/docs/new_wireless_paradigm.htm

Kevin Werbach, "Radio Revolution: The Coming Age of Unlicensed Wireless," New America Foundation (December 2003) http://werbach.com/docs/RadioRevolution.pdf

Jon M. Peha, "Emerging Technology and Spectrum Policy Reform," ITU Workshop on Market Mechanisms for Spectrum Management (Geneva, January 2007) http://www.itu.int/osg/spu/stn/spectrum/workshop_proceedings/Background_Papers Final/Jon\%20Peha\%20ITU\%20spectrum\%20workshop.pdf

Michael Calabrese, "The End of Spectrum 'Scarcity': Building on the TV Bands Database to Access Unused Public Airwaves," New America Foundation, Working Paper 25 (June 2009) - http://www.newamerica.net/files/nafmigration/Calabrese_ WorkingPaper25 EndSpectrumScarcity.pdf

Two points should be emphasized for the discussion which follows: the first is that it is no accident that the conception and promotion of Open Spectrum began in the US. The US had made an earlier and bigger commitment to the development of license exempt radio than any other country, probably as a result of the US Constitution's First Amendment, which basically forbids the passage of laws restricting freedom of speech and press. The real question, for readers of this essay, is: can Open Spectrum gather support and have a policy impact in countries without a free speech tradition? Our assumption is that it can, although it might take longer and require broad coalition building and sustained promotion.

The second point is that the success of Open Spectrum hinges on the development of radios smart enough to manage their own frequency use while minimizing interference. Otherwise, lawmakers will not change the existing institutional framework. Radios fully capable of frequency self-management are already being produced (for the military, at high cost). But more testing is needed to convince skeptics, and more investment in large volume production is needed to bring the cost down. We aren't there yet, which is why TV white spaces are important - or rather, why they could be important (see the discussion below). In any case, they provide a business opportunity for turning automated, dynamic, license exempt frequency management into mass market products.

In 2002, the FCC surprised everyone by asking whether new applications might be allowed to use TV white spaces on a license exempt basis. "White spaces" are areas where the

\footnotetext{
12 "Developing a New Spectrum Policy” - http://www.law.nyu.edu/ecm_dlv/groups/public/@ nyu_law website_centers_information_law_institute/documents/web_copytext/ecm_pro_060818.xml
} 
assignment of specific TV channels is forbidden in order to protect stations using those channels elsewhere. To cite a recent European example, here is a map ${ }^{14}$ showing the "white spaces" which protect digital TV stations using channel 21 in the pink areas. Note that the white spaces are actually larger than the areas of broadcast coverage.

One reason why TV white spaces are so large is that the band planners assumed only TV stations would use these channels and TV stations transmit at high power so they need to be widely separated. However, it is possible for low-power devices to operate completely within a white space so their signals do not impinge on the broadcast coverage areas (as shown at right). ${ }^{15}$ This was the insight that led the FCC to suggest opening white spaces to low-power uses.

The FCC has been careful to assert application neutrality for the TV white spaces, even while suggesting that rural broadband ought to be the prime beneficiary. In fact, more white space is available in rural areas than in cities, and the superior range, foliage penetration and non-line-of-sight propagation of UHF
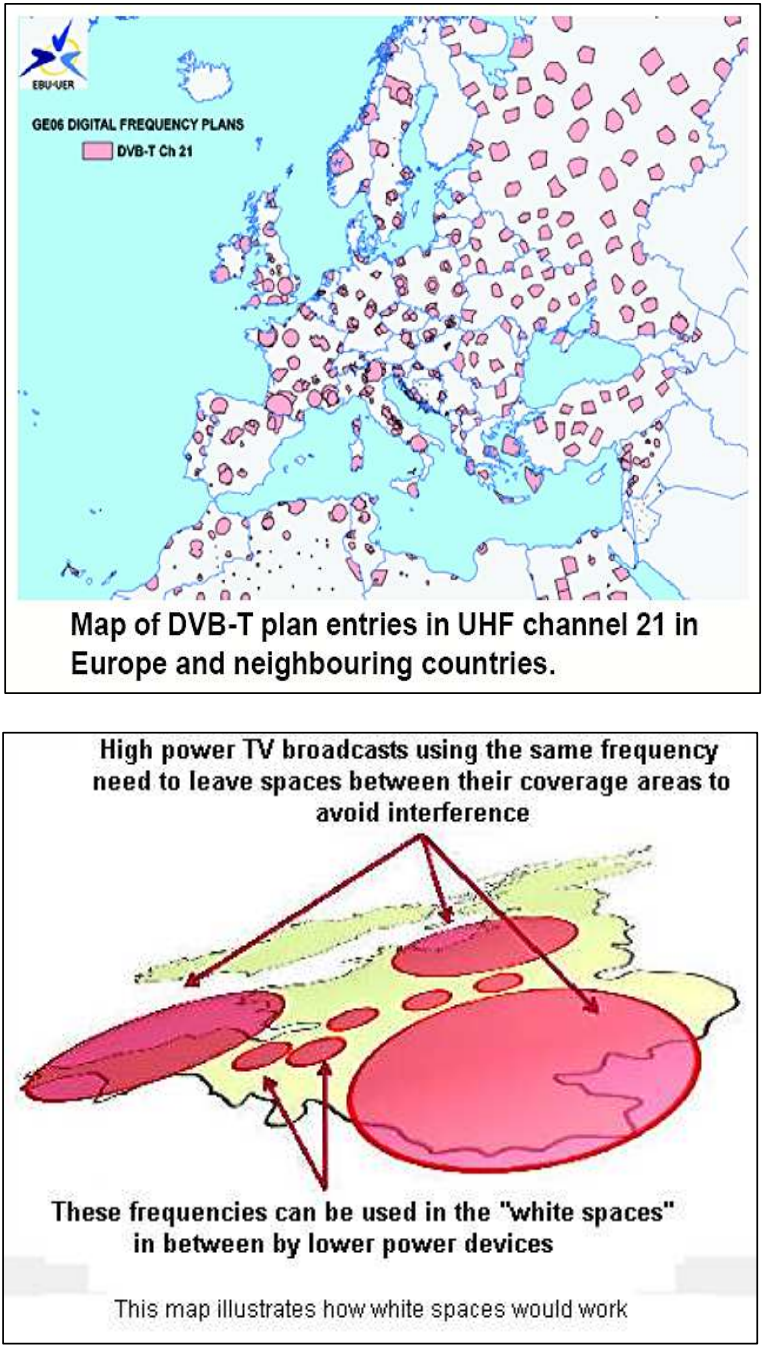
signals can make Internet access economically viable in places where Wi-Fi and cellular infrastructures are too costly - in areas of low population density. ${ }^{16}$

But for white space devices (WSDs) to know what frequencies and power levels are safe to use at a given location, they either need to monitor the radio spectrum to see what channels are free, or they need to know their location so they can ask a geographic database to tell them what is allowed.

13 "ET Docket No. 02-380: Notice of Inquiry in the Matter of Additional Spectrum for Unlicensed Devices Below $900 \mathrm{MHz}$ and in the $3 \mathrm{GHz}$ Band," US Federal Communications Commission, released 20 December 2002 - http://apps.fcc.gov/ecfs/comment/view?id=5508555784

\footnotetext{
${ }^{14}$ Map reprinted from Terry O’Leary, Elena Puigrefagut and Walid Sami, "GE-06: overview of the second session (RRC-06) and the main features for broadcasters," EBU Technical Review 308 (October 2006) - http://tech.ebu.ch/docs/techreview/trev_308-rrc-06.pdf

${ }^{15}$ Map from "UK to use 'White Spaces' to deliver broadband by 2013," Silicon Republic (1 September 2011) - http://siliconrepublic.com/comms/item/23395-uk-to-use-white-spaces-to

16 "Studies have consistently shown that $700 \mathrm{MHz}$ can provide broadband service in rural areas at half to one third the cost of the $1900 \mathrm{MHz}$ personal communications services frequencies used by the cellular carriers... 700MHz can provide broadband services in rural areas at one fourth to one sixth the cost of the $2400 \mathrm{MHz} \mathrm{Wi}-\mathrm{Fi}$ [frequencies]... What this means is that rural areas that were previously 'unreachable' can now get broadband service on an affordable basis." Testimony of Charles C. Townsend before the US Senate Committee on Commerce, Science and Transportation (12 July 2005) - http://www.commerce.senate.gov/pdf/townsend.pdf
} 
When the FCC launched their white space inquiry, they were unsure which frequency management system to support: spectrum monitoring, geo-database lookup or both. But after testing some WSD prototypes, ${ }^{17}$ they decided that monitoring was not yet sufficiently reliable, so portable devices that rely only on monitoring were given a lower power limit than devices using geo-database lookup. ${ }^{18}$ Since the two frequency management techniques were proposed and discussed as alternatives, few people noticed that they have very different political implications. This is unfortunate and WSD advocates should think carefully about the consequences of arguing for a politically risky system which could delay the development of genuinely smart radios while believing they are advancing the cause of Open Spectrum.

Earlier in this chapter we noted that smart radios which can independently and successfully manage their own frequency use eliminate the need for strict government control of spectrum access. ${ }^{19}$ That makes them a force for liberalization and vital for the implementation of Open Spectrum. But a radio which simply follows instructions given by a database - which cannot make independent judgments and does not recognize or learn from patterns in the signal environment - cannot be considered smart or independent. In fact, it is a slave, and standards and regulatory documents describe it that way. ${ }^{20}$ Far from being a liberalizing force, database slaves represent a drastic extension of regulatory control into the radio domain which has been the freest (license exemption). Licensing is superfluous because database control is an even stricter form of regulation.

Geo-database control of WSDs has been tested in China, France, Germany, Indonesia, Japan, Kenya, Malaysia/Singapore, Slovakia, South Africa and the United Kingdom. India may join this group soon. Belgium, Denmark, Finland, Latvia, Philippines, Poland and the UK say they will authorize geo-databases for WSDs; the $\mathrm{US}^{21}$ and Canada ${ }^{22}$ have already done so.

Geo-databases are increasingly seen as the solution to coexistence problems throughout the spectrum: location-aware power limits at $2.4 \mathrm{GHz}$ will enable Wi-Fi to operate at higher powers where interference is not a risk; in the $3.6 \mathrm{GHz}$ band, they will help satellite systems coexist with terrestrial microwave links, military radars and $4 \mathrm{G}$ cellular networks; at $5 \mathrm{GHz}$,

\footnotetext{
${ }^{17}$ Steven K. Jones, et al., Evaluation of the Performance of Prototype TV-Band White Space Devices, Phase II, Report FCC/OET 08-TR-1005, FCC Office of Engineering and Technology (October 2008) http://apps.fcc.gov/ecfs/document/view?id=6520183093

${ }^{18}$ The FCC recently published a pamphlet for small businesses on how to comply with US white space rules, particularly when designing and deploying equipment - http://transition.fcc.gov/Daily_Releases/ Daily Business/2013/db0422/DA-13-808A1.pdf

${ }^{19}$ Maziar Nekovee, "Impact of Cognitive Radio on Future Management of Spectrum," CROWNCOM (2008) - http://arxiv.org/pdf/0903.0276.pdf

${ }^{20}$ See, for example, "ECC Report 186: Technical and operational requirements for the operation of white space devices under geo-location approach," CEPT (January 2013) - http://www.erodocdb.dk/ docs/doc98/official/pdf/ECCRep186.pdf or V. Chen, ed., "Protocol to Access Spectrum Database," draft-ietf-paws-protocol-04, Internet Engineering Task Force (7 May 2013) - http://tools.ietf.org/html/ draft-ietf-paws-protocol-04

${ }^{21}$ The FCC selected 11 firms to administer the databases. Two merged, so now there are 10. "FCC Chairman Genachowski Announces Approval of First Television White Spaces Database and Device," FCC press release (22 December 2011) - http://www.fcc.gov/document/chairman-announces-approvalwhite-spaces-database-spectrum-bridge

${ }^{22}$ Canada initially licensed the use of TV white spaces for broadband access in remote rural areas. This has recently been supplemented with a license exempt, application neutral approach as in the US. See "Framework for the Use of Certain Non-broadcasting Applications in the Television Broadcasting Bands Below 698 MHz," Industry Canada (5 April 2013) - http://www.ic.gc.ca/eic/site/smtgst.nsf/eng/sf10494.html
} 
they are expected to protect radars from the spread of unlicensed radio LANs; the US considers them essential for sharing government frequency bands with private industry.

One feature that makes them so desirable to regulators is that they solve the problem of how to clear a license exempt band for re-allocation to licensed use. The problem has been stopping the use of unlicensed devices whose authorization has lapsed, when the regulator has no idea who owns the devices or where they are located. This is solved by the geo-database's requirement that all connected devices seek frequent re-authorization (every 15 minutes in some countries): The regulator can simply tell the database to stop re-authorizing the devices. And the problem of unknown owners and locations is also solved, at least in the US: "FCC rules... require that a 'Fixed [WSD] Device' MUST register its owner and operator contact information, its device identifier and location..." ${ }^{, 3}$ Repressive regimes can cite that precedent in imposing similar requirements.

The US Commerce Department's Spectrum Management Advisory Committee is so enthused about database-connected devices that they want to make them the new norm for license exempt radio:

"[The National Telecommunications and Information Administration], in coordination with the FCC, should further study the regulatory treatment under the current unlicensed framework for 'cheap, dumb' devices. The Committee generally recommends that in the future 'unconnected' devices should be restricted to legacy bands of spectrum where they are already prevalent (e.g., $900 \mathrm{MHz}, 2.4 \mathrm{GHz}$ ). Policymakers should consider whether such devices should even be further restricted in the future, phasing out their access to very high-quality bands over an appropriate time period..." 24

Note that this recommendation is still only a proposal. But the possibility of connected slave devices leading even US regulators, with their liberal orientation, to phase out access to license exempt spectrum for non-slave devices should make us think very, very, very carefully about the consequences of promoting geo-database look-up systems for WSDs.

The decade-long struggle to introduce WSDs in the US, and now in a growing list of other countries, has been fueled by the hope that WSDs will make possible cheaper broadband access in rural areas and a new wave of innovation as happened at 900 and $2400 \mathrm{MHz}$. A low-cost, low-density technology is surely needed, especially in Africa. However, the temporary but total cutoffs of Internet access in Egypt, Libya and Syria make one wonder if it is wise to give government-sanctioned control centers a "kill switch" for broadband access. ${ }^{25}$ In the US, geo-database administration has been privatized. ${ }^{26}$ But in other countries it might be a government function.

We certainly support the development of rural broadband. But from an Open Spectrum perspective, reliance on geo-database control to accomplish that involves a degree of political risk that may be unacceptable in certain countries. Regulators regard spectrum sensing as too

\footnotetext{
${ }^{23}$ IETF, "Protocol to Access Spectrum Database" - see note 20, supra.

${ }^{24}$ CSMAC Unlicensed Subcommittee, "Presentation of Final Report of Recommendations," US Department of Commerce Spectrum Management Advisory Committee (24 July 2012) http://www.ntia.doc.gov/files/ntia/publications/unlicensed subcommittee finalreport072420122.pdf

25 "Internet censorship in the Arab Spring," Wikipedia - http://en.wikipedia.org/wiki/Internet censorship_in the Arab_Spring. All these shutoffs were attempts by governments to stifle or silence public protests. The term "kill switch" is used by CSMAC in one of their recommendations.

26 “White Space Database Administrators Guide," FCC Encyclopedia - http://www.fcc.gov/ encyclopedia/white-space-database-administrators-guide
} 
unreliable now, but that is the approach which leads to autonomous device operation and less risk of government disruption of private communication channels. It will be a harder road, with success less certain, but at least that path leads to where we want to be. 